negatively correlated with nutritional markers such as serum albumin level (correlation coefficient $r=-0.291 ; P<0.01$ ) and blood urea nitrogen level $(r=-0.161 ; P<0.01)$. The index was positively correlated with inflammatory parameters such as high-sensitivity C-reactive protein $(r=0.212 ; P<0.01)$. Chi-square analyses showed that, compared with patients with no or mild to moderate periodontitis, a significantly larger proportion of patients with severe periodontitis had malnutrition $(P=0.005)$ and inflammation $(P=0.018)$.

It is important to determine whether treatment of periodontitis in hemodialysis patients would result in a lower incidence of inflammation and malnutrition, and whether this would translate into improved cardiovascular outcomes.

Original article Chen LP et al. (2006) Does periodontitis reflect inflammation and malnutrition status in hemodialysis patients? Am J Kidney Dis 47: 815-822

\section{Survival advantage with longer, slower hemodialysis sessions}

Results of two independently performed, large observational studies bring us closer to determining the optimal combination of session length, dose and ultrafiltration rate for hemodialysis; the researchers conclude that prospective, randomized clinical trials are needed.

An analysis of data from the Dialysis Outcomes and Practice Patterns Study, which included 22,000 adult long-term hemodialysis patients from seven countries, has shown that patients with a dialysis session length of $>4 \mathrm{~h}$ had a significantly lower mortality risk than patients who underwent dialysis for $\leq 4 \mathrm{~h}$ (relative risk $[\mathrm{RR}] 0.81 ; P=0.0005)$. Every additional 30 min on dialysis reduced the RR of mortality by $7 \%$ (RR 0.93; $P<0.0001)$. There was a synergistic relationship between $K t / v$ (dialysis dose) and dialysis session duration with regard to mortality risk: at higher $K t / v$, a longer treatment time was more beneficial than the same session length at lower $\mathrm{Kt} / \mathrm{v}$. In addition, an ultrafiltration rate of $>10 \mathrm{ml} / \mathrm{h} / \mathrm{kg}$ was associated with a higher mortality risk than an ultrafiltration rate of $\leq 10 \mathrm{ml} / \mathrm{h} / \mathrm{kg}(\mathrm{RR} 1.09 ; P=0.02)$.

There were similar findings in a multivariate analysis of data from the Australian and New Zealand Dialysis and Transplant Registry, which included 4,171 adult maintenance hemodialysis patients. Subjects who underwent dialysis at a $K t / v$ of $1.30-1.39$ or had a dialysis session length of 4.5-4.9h had a lower mortality risk than patients who received lower dialysis doses or shorter dialysis sessions (hazard ratios 0.79 and 0.80 , respectively; both $P<0.05$ ).

Original articles Saran R et al. (2006) Longer treatment time and slower ultrafiltration in hemodialysis: associations with reduced mortality in the DOPPS. Kidney Int 69: 1222-1228 Marshall MR et al. (2006) Associations of hemodialysis dose and session length with mortality risk in Australian and New Zealand patients. Kidney Int 69: 1229-1236

\section{Fluconazole dose of $800 \mathrm{mg}$ daily is required to reach antifungal plasma levels}

Fungal septicemia caused by Candida spp. is treated with fluconazole. In vitro testing of the effects of fluconazole on Candida spp. indicated that plasma levels of $16-32 \mu \mathrm{g} / \mathrm{ml}$ are necessary to inhibit growth of some Candida spp. effectively. In patients receiving continuous veno-venous hemofiltration or continuous veno-venous hemodialysis, trials of fluconazole infusions of $200-600 \mathrm{mg} /$ day failed to reach the required plasma concentration. Researchers in Germany attempted to determine whether a fluconazole dose of $800 \mathrm{mg} /$ day would produce the required plasma concentration in nine intensive-care patients receiving continuous veno-venous hemofiltration for acute renal failure.

Dialysis was carried out in two consecutive $24 \mathrm{~h}$ periods with an ultrafiltration rate of $1,000 \mathrm{ml} / \mathrm{h}$ on one day and a rate of $2,000 \mathrm{ml} / \mathrm{h}$ on the other, in a randomized order, with predilution of $800 \mathrm{ml} / \mathrm{h}$ and $1,800 \mathrm{ml} / \mathrm{h}$, respectively. Peak fluconazole concentrations of $16-32 \mu \mathrm{g} / \mathrm{ml}$ were reached in all patients. Mean concentrations above $16 \mu \mathrm{g} / \mathrm{ml}$ were maintained for $17.0 \pm 8.0 \mathrm{~h}$ at an ultrafiltration rate of $1,000 \mathrm{ml} / \mathrm{h}$, and for $9.1 \pm 8.3 \mathrm{~h}$ at an ultrafiltration rate of $2,000 \mathrm{ml} / \mathrm{h}$. The treatment was well tolerated.

Although the in vivo concentration of fluconazole necessary for a therapeutic effect is not yet known, the study demonstrates that concentrations known to be effective against Candida spp. in vitro can be reached without adverse effects in critically ill patients.

Original article Bergner R et al. (2006) Fluconazole dosing in continuous veno-venous haemofiltration (CVVHF): need for a high daily dose of $800 \mathrm{mg}$. Nephrol Dial Transplant 21: 1019-1023 